\title{
Moxibustion for Herpes Zoster and Postherpetic Neuralgia: A Meta-Analysis
}

\author{
Yuanen Huang $\mathbb{D},{ }^{1}$ Jingping $W u\left(\mathbb{D},{ }^{2}\right.$ Hongbin Cheng $\mathbb{D},{ }^{3}$ and Yanling Liu $\mathbb{}{ }^{4}$ \\ ${ }^{1}$ Clinical Research on Skin Diseases, Hospital of Chengdu University of Traditional Chinese Medicine, Chengdu, \\ Sichuan 610075, China \\ ${ }^{2}$ Department of Medical Cosmetology, Hospital of Chengdu University of Traditional Chinese Medicine, Chengdu, \\ Sichuan 610075, China \\ ${ }^{3}$ Dermatology Department, Hospital of Chengdu University of Traditional Chinese Medicine, Chengdu, Sichuan 610075, China \\ ${ }^{4}$ Surgery of Chinese Medicine, Hospital of Chengdu University of Traditional Chinese Medicine, Chengdu, Sichuan 610075, China
}

Correspondence should be addressed to Hongbin Cheng; hongbincheng2007@126.com

Received 19 January 2021; Accepted 4 May 2021; Published 22 May 2021

Academic Editor: Wei Wang

Copyright $\odot 2021$ Yuanen Huang et al. This is an open access article distributed under the Creative Commons Attribution License, which permits unrestricted use, distribution, and reproduction in any medium, provided the original work is properly cited.

Background. Herpes zoster (HZ) is a disease that mainly causes severe segmental neuralgia and vesicles after infection with herpes zoster virus (VZV). At the same time, more than 9 to 34 percent of patients have postherpetic neuralgia (PHN) present with chronic pain for months or even years. Moxibustion has been used to treat herpes zoster and postherpetic neuralgia for many years; however, there has been no comprehensive study to evaluate the efficacy and safety of moxibustion in the treatment of herpes zoster and postherpetic neuralgia. More studies evaluated the combined effects of acupuncture and moxibustion. Therefore, the purpose of this systematic review is to evaluate their efficacy and safety, so as to provide an evidence-based basis for the clinical application of moxibustion in the treatment of HZ and PHN. Method. The literature search was conducted in nine Chinese and English databases, and randomized controlled trials were pooled from their inceptions to June 2020. The included literature was screened, and data were extracted. RevMan 5.3 software and Stata software were used for statistical analysis. The primary outcome was the total effect. The secondary outcomes include VAS, NRS, and time of analgesia. Outcomes. From a total of 1957 identified studies, 31 were included in analysis $(N=2334$ cases). 31 RCTs contained the experimental sample of 1185 cases and the control sample of 1149 cases reported efficiency of different moxibustions in the treatment of herpes zoster, statistical heterogeneity inspection without heterogeneity. So, we used the fixed-effects model, merge effect quantity OR $=3.89$ (95\% CI: 2.88 5.25), $Z=8.86$, and it suggested sample merger analysis was statistically significant. Also, the moxibustion, compared to other methods in the treatment of herpes zoster and herpes zoster neuralgia efficiency, increased significantly. The VAS scales, $\mathrm{WMD}=1.69$ (95\% CI: 1.17 2.22), and the time of analgesia, WMD $=2.41$ (95\% CI: 3.26 1.73), indicated that moxibustion surpassed others in the relief of pain. NRS was just reported in one study. It was not statistically significant. There was no significant difference in adverse effects $\mathrm{OR}=0.61$ (95\% CI: 0.33 1.13), $Z=1.56(P=0.12)$. Conclusion. Moxibustion has obvious advantages over other therapies in the treatment of $\mathrm{HZ}$ and $\mathrm{PHN}$. However, due to the obvious publication bias, the interpretation of the results should be cautious, and more rigorous randomized controlled clinical studies should be included to further confirm the results in the future.

\section{Introduction}

Herpes zoster (HZ) is known as snake-like sore, fire girdle sore, or spider sore in traditional Chinese medicine. The cause of disease has not been determined; at present, it is believed that the pathogenesis is that, after the initial infection of varicella zoster virus in people with low immunity (mostly children), the virus is latent in the ganglion of the posterior root of the spinal cord. After being activated by various incentives, the virus grows and multiplies in the neurons, leading to ganglion inflammation and neuralgia. The virus then travels with the nerve to the skin and causes 
segmental vesicles [1]. Neuralgia can present as tingling, itching, burning, etc., which is one of the most typical symptoms of HZ. Studies have shown that postherpetic neuralgia (PHN) occurs in more than 9 to 34 percent of patients, with chronic pain lasting months or years having detrimental effects on sleep, daily activities, and quality of life [2].

Western medicine treats herpes zoster with antiviral, nourishing nerve, anti-inflammatory and analgesic methods, and tricyclic antidepressants, opioids, gabapentin, lidocaine patch, capsaicin, and other therapies in pain relief, but the efficacy is limited [3], and the drug's side effects on patients also limit its use [4], while acupuncture and moxibustion combined therapy has a better performance in relieving pain and relieving symptoms [5-7]. Meanwhile, the study of $\mathrm{Li}$ et al. [8] showed that the use of acupuncture and moxibustion therapy is cheaper than Western medicine in cost so as to reduce the financial burden of patients.

Moxibustion therapy is a method of burning and ironing the acupoints or diseased parts by means of the heat of moxibustion fire and the action of drugs, so as to warm the meridians to dissipate the cold, nourish the Yang to get rid of the stasis, dissipate the knot, induce heat to the outside, and prevent diseases and health care. There are many kinds of moxibustion, moxibustion from medicine, white mustard moxibustion, fine moxibustion, Cantharide moxibustion, and so on); moxibustion methods are divided into direct moxibustion, indirect moxibustion, suspension moxibustion, practical moxibustion, and so on [9]. Different methods have different directions of action, but the thermothermal action is a common feature. Kai-Yu et al. [10] and Petersen [11] found that warm stimulation of moxibustion could improve skin permeability, promote wound healing, drug percutaneous absorption, and treat skin infectious diseases, indirectly proving that moxibustion may have its unique advantages in the treatment of herpes zoster and neuralgia.

Research shows that, in clinical practice, use of different moxibustions combined with acupuncture, internal and external use of drugs, phototherapy, and other methods in the treatment of herpes zoster has a significant effect, but many studies focus more on the effectiveness of acupuncture and moxibustion comprehensive therapy (including acupuncture and moxibustion, cupping, and so on), treatment of herpes zoster, and action mechanism $[5,12,13]$. There is a lack of independent evaluation of moxibustion therapy in the treatment of HZ and PHN in the literature. Thus, the purpose of this study was to evaluate the effectiveness of moxibustion in relieving the neuralgia caused by $\mathrm{HZ}$ and $\mathrm{PHN}$ in a more comprehensive, systematic, and rigorous way, to make up the blank of moxibustion research in the treatment of $\mathrm{HZ}$ and $\mathrm{PHN}$, meanwhile, to provide reliable evidence for the treatment of $\mathrm{HZ}$ and $\mathrm{PHN}$ by use of moxibustion.

\section{Methods}

2.1. Literature Search. Five English (PubMed, Embase, Cochrane Central, Web of Science, and Springer Link) and four Chinese (CBM, CNKI, CQVIP, and Wanfang Data) databases were searched from inceptions to June 2020. Search terms were grouped according to condition (herpes zoster, zoster, neuralgia, postherpetic neuralgia, and variants), intervention (acupuncture, moxibustion, and variants), and study design (randomized, controlled, and variants).

\subsection{Eligibility Criteria}

2.2.1. Types of Studies. Any randomized trials, whether double-blind, single-blind, or unblinded, and regardless of publication status, language and length of trial were considered for inclusion. When administering moxibustion, patients are typically aware of methods. This makes blinding difficult. In this study, there were no special requirements for blinding subjects or administrators.

\subsubsection{Types of Participants. Participants with $\mathrm{HZ}$ or $\mathrm{PHN}$} who were adults ( $>18$ years), regardless of sex or ethnicity, were included in this study. There are definite diagnostic criteria for HZ. Because PHN's diagnostic criteria are inconsistent, we defined $\mathrm{PHN}$ as pain persisting for more than 1 month or any of the abovementioned criteria included into the literature.

2.2.3. Types of Interventions and Controls. If the experimental intervention is moxibustion, the control intervention can be one or more other therapies including acupuncture, drugs, cupping, and phototherapy, except moxibustion. If the experimental intervention is moxibustion combined with other therapies, the control intervention must be the same as other therapies in the experimental group.

2.2.4. Types of Outcomes. Primary outcome will be the efficiency of patients' condition improvement. Secondary outcome will include pain intensity (measured by the Visual Analogue Scale (VAS), Numerical Rating Scale (NRS), and the time of analgesia) and adverse effects (including infection and empyrosis).

2.2.5. Treatment Cycle. The two groups had the same treatment cycle, or the outcome was cure.

\subsection{Exclusion Criteria}

2.3.1. Types of Participants. Participants with complications of herpes zoster (Ramsay Hunt syndrome, zoster opthalmicus, zoster sine herpete, visceral or disseminated zoster, and bacterial infections) or included immunocompromised patients (e.g., HIV, cancer, diabetes, pregnant, or breastfeeding) will be excluded.

2.3.2. Sample Size. Studies with a sample size of less than 30 in the experimental group and/or control group will be ineligible. 
2.3.3. Experimental Data. It is rejected if the experimental description is unclear or the experimental data are incorrect or inaccurate so that it cannot be extracted; meanwhile, the studies' authors cannot be contacted to obtain the data.

2.4. Extraction of Data. Retrieval results were imported into literature management software Endnote X9 for review. According to titles and abstracts, two researchers independently screened studies. If titles and abstracts could not determine whether the studies could be included, the full text is reviewed. At the same time, the two researchers independently extracted data from included literatures into a predefined spreadsheet, including the title, author, year, treatment cycle, sample size, interventions, effective events, lost to exit, follow-up time, adverse reactions, and the Jadad score. If there was a difference, it would be solved by two researchers with a third researcher through discussion.

2.5. Quality Assessment. Quality assessment was made independently by two researchers. The two researchers independently used the modified Jadad Scale and the Cochrane Collaboration's risk of bias tool to cross check the quality of the literature. The modified Jadad scale evaluates the literature from four aspects: "random sequence generation," "random hiding," "blind method," and "loss to follow-up and exit." A score of 1-3 is of low quality and 4-7 is of high quality. The Cochrane Collaboration's risk of bias tool assesses from 7 aspects: "random sequence generation," "random concealment," "blind subjects and interveners," "blind evaluators," "complete reporting of outcome data," "selective reporting of study results," and "other biases." The risk of bias for each item would be graded as "low risk of bias," "unclear risk of bias," or "high risk of bias." If disagreement was seen in assessments, this was resolved through discussion with a third researcher.

2.6. Date of Analysis. RevMan 5.3 software and Stata software were used for data statistics (The Nordic Cochrane Centre). Continuous data were presented as weighted mean difference (WMD) or standardized mean difference (SMD), and dichotomous data were presented as odds ratio (OR), with $95 \%$ confidence intervals (CI). A $Z$ test was used for the statistical hypothesis test, and the test level was set as $P=0.05 . I^{2}$ was used for quantitative analysis of statistical heterogeneity. When $P>0.05$ and $I^{2}<50 \%$, all studies were statistical homogeneous, and a fixed-effects model (FE) was used for analysis. When $P<0.10, I^{2}>50 \%$, statistical heterogeneity was considered present, and a random-effects model (RE) was used for analysis. If 10 or more studies were included in a meta-analysis, we would explore publication bias through the funnel regression method or Egger's regression method. Sensitivity analysis was carried out using the trim and fill method and one-by-one removal method.

\section{Results}

3.1. Description of Studies. 1669 Chinese citations and 288 English citations were searched from the database, and 891 duplicate references were excluded. 884 citations were excluded based on screening of titles and abstracts, and 182 citations were reviewed in full text. 31 randomized controlled trials (RCTs) met the inclusion criteria. The studies' screening is shown in Figure 1. There are 19 RCTs about HZ and 12 RCTs about PHN, the total number of participants was 2334, and the characteristics of participants in included studies are shown in Figure 2. All studies were conducted in China. Six studies included more than one treatment group, and those additional treatment arms were excluded from this review [14-19].

3.2. Risk of Bias in Included Studies. The total score of improved Jadad is 7 points, with 27 articles of low quality scoring 1-3 points and 4 articles of high quality scoring 4-7 points.

The recommendations in the methods section of the Cochrane Handbook 5.3.3 were used to assess the risk of bias. All included studies mentioned the randomization methods used. 19 studies used a random number table to divide patients into experimental and observation groups. Two studies used a computer-generated random number, one study used central random distribution, eight studies just mentioned only random words, and one study was randomly assigned in the order of visits. Four studies used distribution of hidden. Three studies mentioned blinding details for evaluators and statisticians. Seven studies described the number and reason of shedding, one study only described the number of shedding, and one study did not describe the number of shedding.

A study had a mistake in date [20], a study's was not described in detail [21], and others found no significant source bias after reviewing the full text (Figures 3 and 4).

\subsection{Curative Effect Analysis}

3.3.1. Primary Outcome Efficiency. 31 RCTs [14-44] containing the experimental sample of 1185 cases and the control sample of 1149 cases reported efficiency of different moxibustions in the treatment of herpes zoster, statistical heterogeneity inspection without heterogeneity $(P=0.98$, $I^{2}=0 \%$ ).So, we used the fixed-effects model, merge-effect quantity $\quad \mathrm{OR}=3.89 \quad(95 \% \quad \mathrm{CI}: \quad 2.88 \sim 5.25), \quad Z=8.86$ $(P<0.00001)$; it suggested sample merger analysis was statistically significant. Also, the moxibustion's efficiency, compared to other methods in the treatment of herpes zoster and herpes zoster neuralgia, increased significantly (Figure 5).

3.3.2. Secondary Outcome VAS and NRS. The 20 studies $[14,16-19,22,24-29,31,32,35-38,42,43]$ involved 733 patients in the experimental group and 718 patients in the control group. VAS before and after treatment were reported, and the difference in VAS before and after treatment was calculated. The heterogeneity test showed high heterogeneity $\left(P<0.00001, I^{2}=88 \%\right), \mathrm{WMD}=1.69$ (95\% CI: 1.17 2.22), $Z=6.32 \quad(P<0.00001)$, indicating that the 


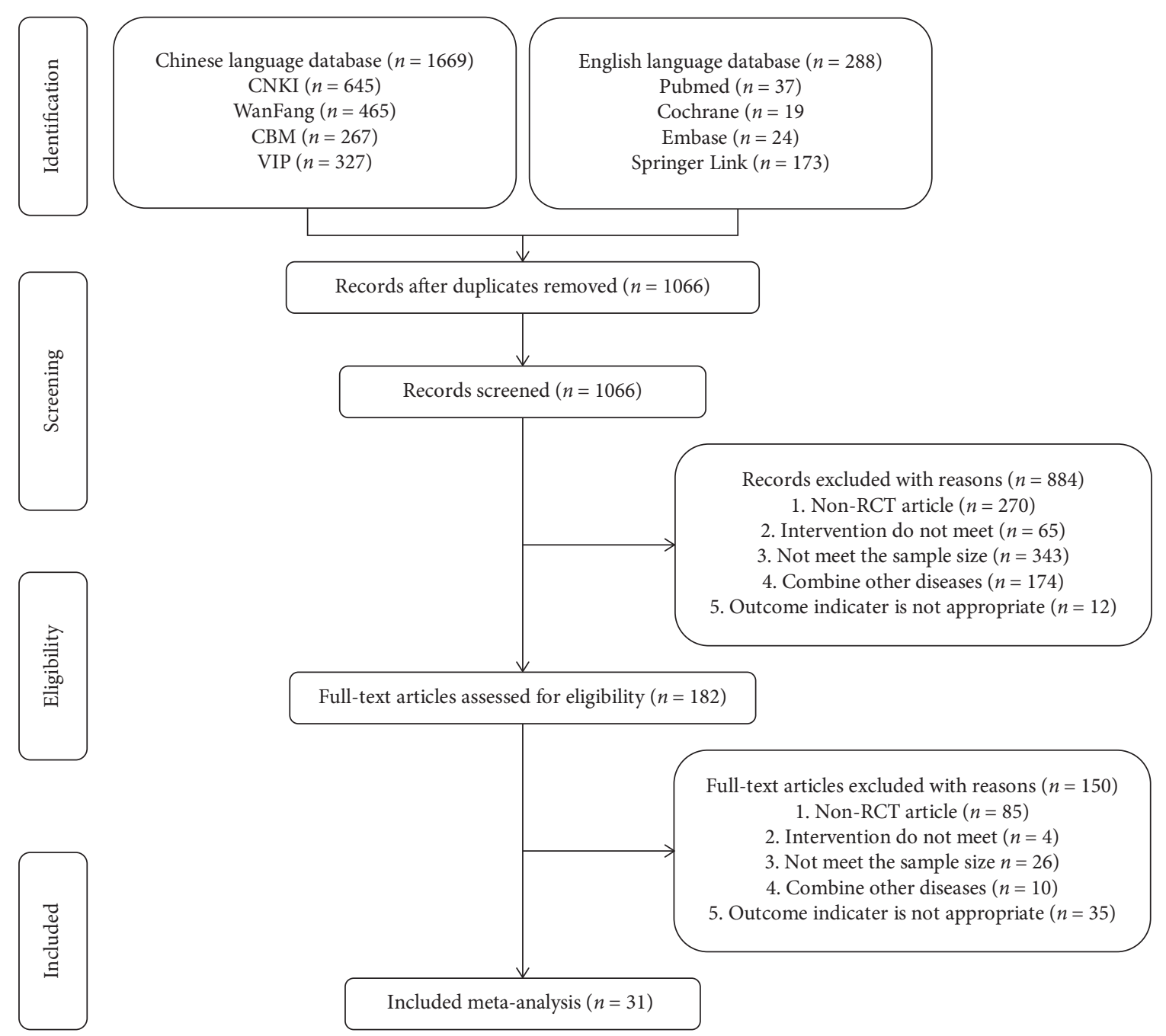

FIGURE 1: Study selection flow chart.

combined analysis of the samples in the studies were statistically significant. Compared with other nonmoxibustion methods, the difference in VAS before and after treatment with moxibustion for herpes zoster and herpes zoster neuralgia was larger than that of other therapies, indicating that moxibustion could better relieve pain than other therapies (Figure 6).

NRS was reported in one study [40]. WMD $=0.71(95 \%$ CI: $-0.87 \sim 2.29$ ), indicating that the combined analysis of the samples in the study was not statistically significant. It did not show that moxibustion relieves the pain better than other therapies. Heterogeneity was not applicable because the number of studies included was insufficient (Figure 7).

\subsubsection{The Time of Analgesia. 16 studies} [14-17, 20, 21, 23, 25, 30, 33, 34, 36, 38, 39, 41, 44] involving sample group 645 cases and control group 622 cases reported the patient's pain time, and heterogeneity inspection shows high heterogeneity $\left(P<0.00001, I^{2}=91 \%\right)$; by using the random-effects model, merge effect quantity of $\mathrm{WMD}=2.41$ (95\% CI: 3.26 1.73), $Z=6.32(P<0.00001)$, suggesting the studies' samples merger analysis was statistically significant, compared with other methods of moxibustion and moxibustion could shorten the time of herpes zoster and herpes zoster neuralgia pain significantly (Figure 8).

3.4. Adverse Effects. 12 studies [15-17, 19, 26, 27, 29, 31, $33,35,36,38$ ] just mentioned "adverse effects," including 7 studies reporting adverse reactions, involved in experimental group 451 cases and control group 447 cases. Heterogeneity analysis $\left(P=0.19, I^{2}=31 \%\right)$, using the fixedeffects model, merge effect quantity OR $=0.61$ (95\% CI: $0.33 \sim 1.13), Z=1.56(P=0.12)$, and merge effect quantity had no statistical significance in the studies, which cannot explain that there was no difference between moxibustion and nonmoxibustion in treating herpes zoster and neuralgia (Figure 9). No serious adverse reactions were found in the 31 RCTs.

3.5. Publication Bias. The funnel plot was drawn to show the asymmetry of scatter point distribution, and Egger's regression method was used to test publication bias. Egger's test showed $t=9.39 \quad(P<0.001,95 \% \quad \mathrm{CI}: 1.78 \sim 2.77)$; 


\begin{tabular}{|c|c|c|c|c|c|c|c|c|c|c|}
\hline \multirow{2}{*}{ Author } & \multirow{2}{*}{ Year } & \multirow{2}{*}{$\begin{array}{c}\text { Sample } \\
\text { size (e/cI) }\end{array}$} & \multirow{2}{*}{$\begin{array}{l}\text { Design } \\
\text { of } \\
\text { study }\end{array}$} & \multirow{2}{*}{$\begin{array}{l}\text { Baseline } \\
\text { comparability }\end{array}$} & \multicolumn{2}{|c|}{ Intervention } & \multirow{2}{*}{$\begin{array}{l}\text { Outcome } \\
\text { measures }\end{array}$} & \multirow{2}{*}{$\begin{array}{l}\text { Generation of } \\
\text { random sequences }\end{array}$} & \multirow{2}{*}{ Jadad } & \multirow{2}{*}{ Follow (d) } \\
\hline & & & & & Experimental group & Control group & & & & \\
\hline ChengYe Lei & 2013 & $39 / 37$ & RCT & Y & Thunder and fire moxibustion + famciclovir & Famciclovir & (1)(4) & Registration order & 0 & 13 \\
\hline Dan Wang & 2015 & $35 / 30$ & RCT & Y & $\begin{array}{l}\text { Moxibustion on heat-sensitive acupoints + longdan } \\
\text { xiegan decoction + acyclovir + erwei badu powder }\end{array}$ & $\begin{array}{c}\text { Longdan xiegan decoction + acyclovir + erwei } \\
\text { badu powderbadu powder }\end{array}$ & (1)(4)(5) & $\begin{array}{l}\text { Random number } \\
\text { table method }\end{array}$ & 2 & 30 \\
\hline DongBo Cao & 2018 & $43 / 43$ & RCT & Y & $\begin{array}{l}\text { Western medicine+traditional chinese medicine+ } \\
\text { thermal moxibustion }\end{array}$ & $\begin{array}{l}\text { General drug + western medicine + traditional } \\
\text { chinese medicine }\end{array}$ & (1)(4) & Random & 1 & $N$ \\
\hline EnHu Zhang & 2004 & $30 / 31$ & RCT & Y & Circling moxibustion & Laser & (3)(4) & Random & 1 & $N$ \\
\hline EnYu Zhang & 2019 & $32 / 32$ & RCT & Y & Needle warming through moxibustion & Acupuncture & (2)(4) & Random & 1 & $N$ \\
\hline FeiE Hu & 2013 & $63 / 63$ & RCT & Y & Circling moxibustion + general drug & Compound calamine lotion + general drug & (3)(4) & $\begin{array}{l}\text { Random number table } \\
\text { method }\end{array}$ & 2 & 60 \\
\hline Feng Chen & 2014 & $30 / 30$ & RCT & Y & $\begin{array}{l}\text { Line medicine moxibustion + electro-acupuncture + } \\
\text { pricking-cupping bloodletting method }\end{array}$ & $\begin{array}{l}\text { Electro-acupuncture + pricking-cupping } \\
\text { bloodletting method }\end{array}$ & (1)(4)(3) & $\begin{array}{l}\text { Random number } \\
\text { table method }\end{array}$ & 2 & 30 \\
\hline GuoFu Huang & 2012 & $35 / 36$ & RCT & Y & Cotton moxibustion & Valaciclovir + vitamin bl & (1)(4)( & $\begin{array}{l}\text { Random number } \\
\text { table method }\end{array}$ & 2 & 60 \\
\hline GuoMing Pu & 2017 & $60 / 60$ & RCT & Y & Cotton moxibustion & Valaciclovir & (1)(4) & $\begin{array}{l}\text { Random number } \\
\text { table method }\end{array}$ & 2 & 90 \\
\hline HongQing Ma & 2008 & $33 / 33$ & RCT & Y & Ashi point direct moxibustion + encircled needling & Encircled needling & (1)(4)(6) & $\begin{array}{l}\text { Random number } \\
\text { table method }\end{array}$ & 5 & 60 \\
\hline Hui Zhou & 2020 & $32 / 32$ & RCT & Y & $\begin{array}{c}\begin{array}{c}\text { Grain-moxibustion +surround moxibustion + general } \\
\text { drug }\end{array}\end{array}$ & General drug & (1)(4) & $\begin{array}{l}\text { Random number } \\
\text { table method }\end{array}$ & 2 & N \\
\hline HuiFen Pan & 2009 & $33 / 32$ & RCT & Y & Cotton moxibustion & Western medicine & (1)(4) & Random & 1 & $N$ \\
\hline Jia Liu & 2009 & $55 / 54$ & RCT & Y & Cotton moxibustion + encircled needling + acusector & $\begin{array}{c}\text { Tapping and } \\
\text { Cupping + encircledneedling + acusector }\end{array}$ & (1)(4)(3) & Central random & 6 & 90 \\
\hline Jing Yu & 2011 & $30 / 30$ & RCT & Y & Taiyi moxa stick + surrounded needling & Surrounded needling & (1)(4) & Random & 2 & $N$ \\
\hline JunWei Kan & 2013 & $33 / 33$ & RCT & Y & Grain-moxibustion + acupuncture at jiaji point & Acupuncture at jiaji point & (1)(4)(6) & $\begin{array}{l}\text { Random number } \\
\text { table method }\end{array}$ & 6 & 60 \\
\hline Ling Qiu & 2015 & $40 / 40$ & RCT & Y & $\begin{array}{l}\text { Grain-moxibustion + routine aupuncture + paravertebral } \\
\text { points electroacupuncture + ashi points surround needling }\end{array}$ & $\begin{array}{l}\text { Routine aupuncture }+ \text { paravertebral points } \\
\text { electroacupuncture }+ \text { ashi points surround } \\
\text { needling }\end{array}$ & (1) & $\begin{array}{l}\text { Random table } \\
\text { method }\end{array}$ & 3 & 90 \\
\hline Min Zhang & 2007 & $38 / 34$ & RCT & Y & Surround moxibustion + encircled needling & Encircled needling & (3)(4)(5) & $\begin{array}{l}\text { Random number } \\
\text { table method }\end{array}$ & 2 & $N$ \\
\hline Qing Wang & 2017 & $56 / 44$ & RCT & Y & Sparrow-pecking moxibustion + acyclovir & Acyclovir & (1)(5) & $\begin{array}{l}\text { Random number } \\
\text { table method }\end{array}$ & 2 & $\mathrm{~N}$ \\
\hline RongJuan Cao & 2018 & $30 / 30$ & RCT & Y & $\begin{array}{c}\text { Cotton moxibustion }+ \text { acyclovir }+ \text { celecoxib }+ \\
\text { mecobalamine }+ \text { compound calamine lotion }+ \text { acyclovir }\end{array}$ & $\begin{array}{l}\text { Acyclovir }+ \text { celecoxib }+ \text { mecobalamine }+ \\
\text { compound calamine lotion }+ \text { acyclovir }\end{array}$ & (1)(3) & $\begin{array}{l}\text { Random number } \\
\text { table method }\end{array}$ & 2 & 90 \\
\hline RuXing Yang & 2018 & $30 / 30$ & RCT & Y & Wick moxibustion + valaciclovir + vitamin bl & Valaciclovir + vitaminbl + acupuncture & (1)(4)(3) & $\begin{array}{l}\text { Random number } \\
\text { table method }\end{array}$ & 2 & N \\
\hline $\begin{array}{l}\text { XiaoHong } \\
\text { Quan }\end{array}$ & 2017 & $31 / 30$ & RCT & Y & Suspension moxibustion + general drug & General drug & (3)(6) & $\begin{array}{l}\text { The software generates } \\
\text { randomnumbers }\end{array}$ & 6 & 30 \\
\hline $\begin{array}{l}\text { XiaoYang } \\
\text { Zhang }\end{array}$ & 2018 & $30 / 30$ & RCT & Y & Cotton moxibustion + filiform needle puncture & Filiform needle puncture & (1)(3)(3)(3) & $\begin{array}{l}\text { Random number } \\
\text { table method }\end{array}$ & 2 & 28 \\
\hline Xin Zhang & 2016 & $30 / 30$ & RCT & Y & Thunder and fire moxibustion + surrounded needling & Surround needling & (1)(6) & $\begin{array}{l}\text { Random number } \\
\text { table method }\end{array}$ & 2 & $N$ \\
\hline Yan Du & 2014 & $40 / 40$ & RCT & Y & Herbalstring moxibustion & Indometacin enteric-coated tablets & (1)(6) & $\begin{array}{l}\text { The software generates } \\
\text { random numbers }\end{array}$ & 2 & $N$ \\
\hline Yan Li & 2006 & $40 / 38$ & RCT & Y & Moxa stick moxibustion + acusector & Acusector + tdp & (3)(4) & Random & 1 & 60 \\
\hline Yan Teng & 2014 & $34 / 34$ & RCT & Y & $\begin{array}{l}\text { Moxibustion + needlewarmingthroughmoxibustion } \\
+ \text { acupuncture at jiaji point }\end{array}$ & Acupuncture at jiaji point & (1)(6) & $\begin{array}{l}\text { Random number } \\
\text { table method }\end{array}$ & 3 & 90 \\
\hline YingHao Qu & 2019 & $40 / 40$ & RCT & Y & Wick moxibustion + acyclovir & Acyclovir & (1)(4)(5) & $\begin{array}{l}\text { Random number } \\
\text { table method }\end{array}$ & 2 & 60 \\
\hline YongDui Ruan & 2009 & $51 / 49$ & RCT & Y & Thermal moxibustion & Acupuncture + tdp + cupping & (1)(3) & $\begin{array}{l}\text { Random number } \\
\text { table method }\end{array}$ & 2 & $N$ \\
\hline YuLin Zeng & 2017 & $45 / 45$ & RCT & Y & Wick moxibustion & Acyclovir + vitaminb12 & (1)(3)(3) & $\begin{array}{l}\text { Random number } \\
\text { table method }\end{array}$ & 2 & $N$ \\
\hline ZhiGang Tang & 2011 & $42 / 38$ & RCT & Y & Wick moxibustion & Western medicine & (1)(4) & Random & 1 & $N$ \\
\hline ZhiJuan Wen & 2019 & $30 / 30$ & RCT & Y & Herbalstring moxibustion combined with famciclovir & Famciclovir & (3)(4)(5) & Random & 1 & $N$ \\
\hline
\end{tabular}

(1) VASa (2) NRSa (3) The time of analgesiaa (9) Effective ratea (3) sequelaa $\odot$ adverse reaction; $\mathrm{Y}=\mathrm{Yes} ; \mathrm{N}=$ Not Described; $\mathrm{E}=$ Experimental group; $\mathrm{C}=$ Control group

FIGURE 2: Characteristics of participants in included studies.

Random sequence generation (selection bias)

Allocation concealment (selection bias) Blinding of participants and personnel (performance bias) Blinding of outcome assessment (detection bias)

Incomplete outcome data (attrition bias) Selective reporting (reporting bias)

Other bias

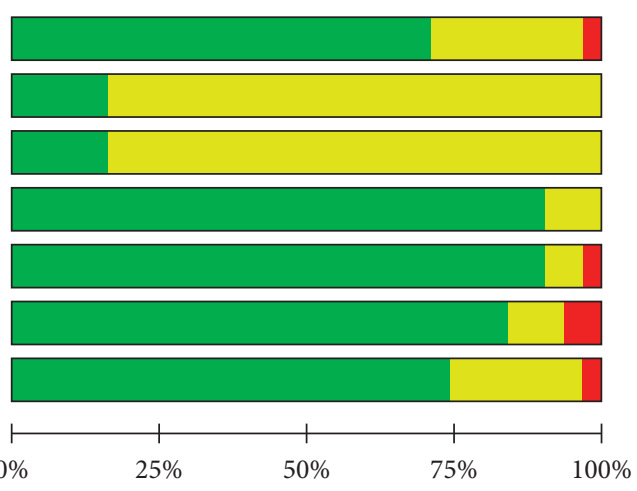

Low risk of bias

Unclear risk of bias

High risk of bias

Figure 3: Risk of bias scale graph. 
ChengYe Lei, 2013

Dan Wang, 2015

DongBo Cao, 2019

EnHu Zhang, 2004

EnYu Zhang, 2019

FeiE Hu, 2013

Feng Chen, 2014

GuoFu Huang, 2012

GuoMing Pu, 2017

HongQing Ma, 2008

Hui Zhou, 2020

HuiFen Pan, 2009

Jia Liu, 2009

Jing Yu, 2011

JunWei Kan, 2013

Ling Qiu, 2015

Min Zhang, 2007

Qing Wang, 2017

RongJuan Cao, 2018

RuXing Yang, 2018

XiaoHong Quan, 2017

XiaoYang Zhang, 2018

Xin Zhang, 2016

Yan Du, 2014

Yan Li, 2006

Yan Teng, 2014

YingHao Qu, 2019

YongDui Ruan, 2009

YuLing Zeng, 2017

ZhiGang Tang, 2011

ZhiJuan Wen, 2019
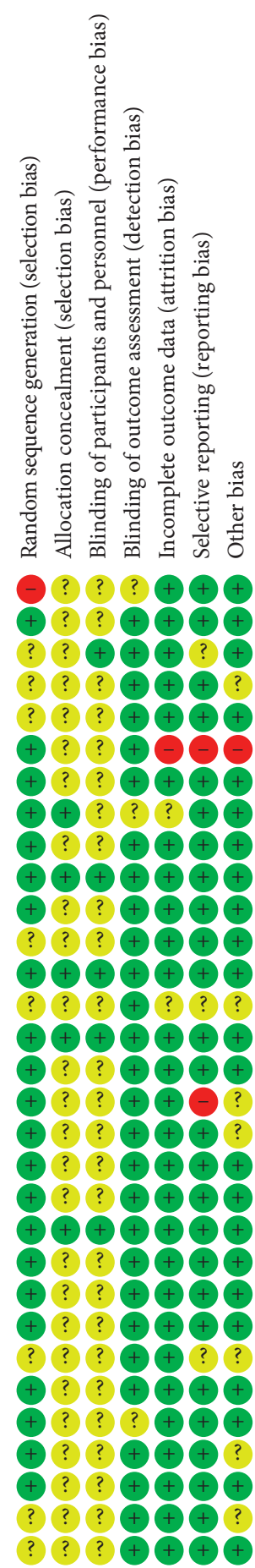

FIgURE 4: Summary chart of risk of bias. meanwhile, the regression line in the graph did not go through the origin, it hinted the existence of publication bias, and publication bias led to asymmetry of the funnel plot (Figures 10-12).

3.6. Sensitivity Analysis. Due to publication bias in the included studies, the sensitivity analysis was carried out on the method of the changes of the observation results after being eliminated one by one in the 31 included studies and trim and fill method by STATA software after the supplementary funnel plot $(P<0.001)$ was little changed compared with that before the supplementary funnel plot. The results showed little change after the study was eliminated one by one, indicating that the results were stable (Figures 13-15).

\section{Discussion}

$\mathrm{HZ}$ and PHN brought about a huge pain and economic burden on people around the world [45]. They seriously 


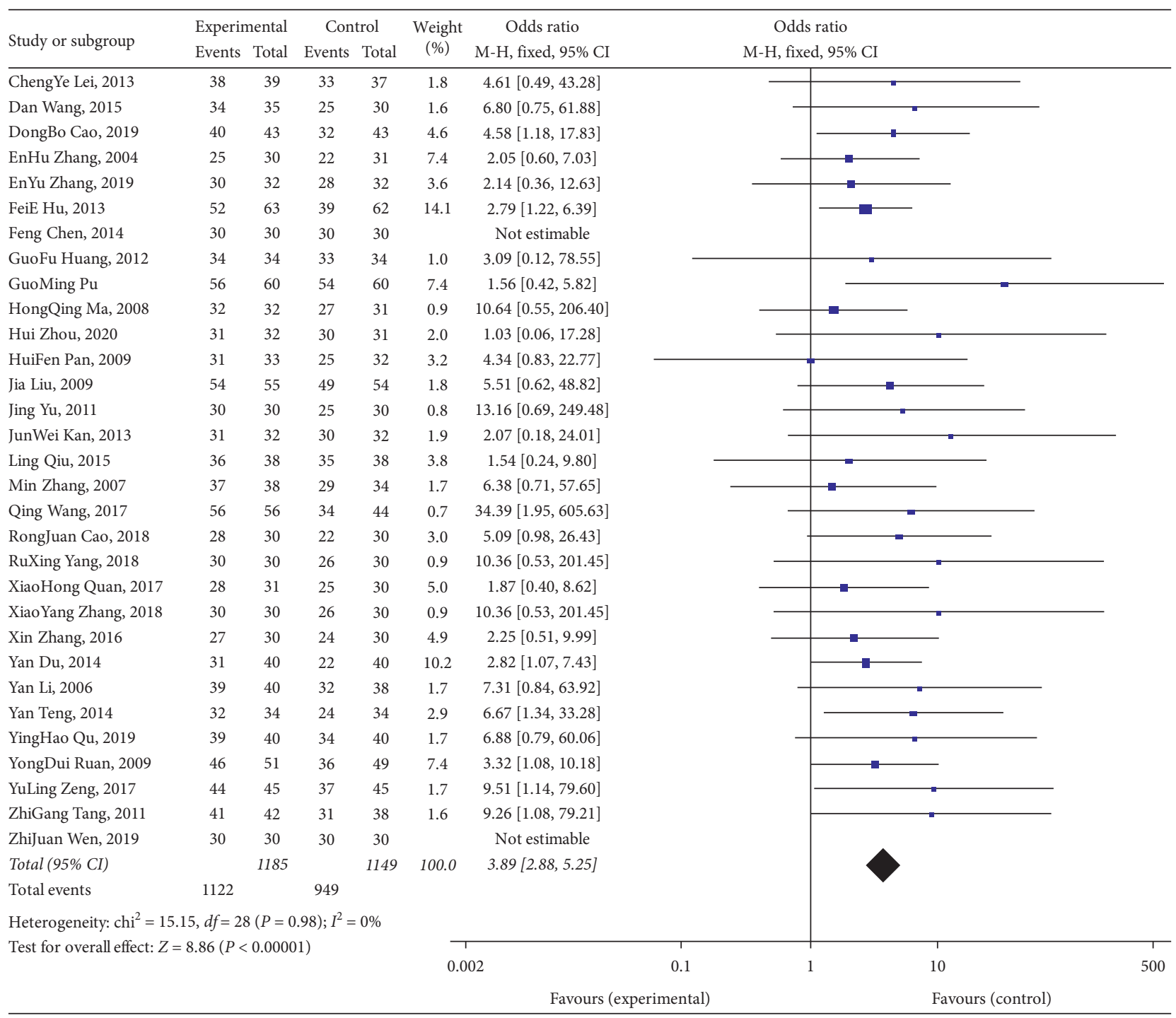

FIgURE 5: Efficiency forest plot.

affected people's health and interfere with the normal life work [46]. Two studies [47, 48] had shown that age, sex, and low immunity were significantly associated with onset, recurrence, and complication. The aging of the population is increasing the burden of the disease on the society. The global incidence of the disease is increasing year by year, about 3-5/1000 person-year, with a recurrence rate of $12 /$ 1000 person-year $[47,49]$. Antiviral drugs effective against $\mathrm{HZ}$ showed no improvement in the relief of PHN, and so far, there is no satisfactory treatment for PHN $[50,51]$, so researchers and doctors can only recommend shingles vaccine for the elderly to reduce $\mathrm{HZ}$ and PHN $[52,53]$, while there has been no clear report on the effectiveness of vaccination in patients with severe immunodeficiency disease $[54,55]$. Therefore, to explore the effective treatment of $\mathrm{HZ}$ and PHN is still the direction of the efforts of scholars.
From the meta-analysis involving 31 RCTs, moxibustion has obvious advantages in the treatment of $\mathrm{HZ}$ and PHN, compared with other nonmoxibustion methods, and the analgesic time and VAS concerned in this study performed better in the experimental group than the control group. In this study, inclusion and exclusion criteria were strictly implemented. Clear diagnostic criteria, efficacy evaluation criteria, simple intervention measures, and appropriate sample size enabled the study to have a high level of evidence, which could provide more reliable evidence-based medical evidence for clinical practice.

Limitations: (1) All the included citations in this study were in Chinese, and there was no RCT study in English. (2) Without manual retrieval, grey reference may be omitted. (3) The quality of the included reference is generally low, some studies have no detailed description of random 


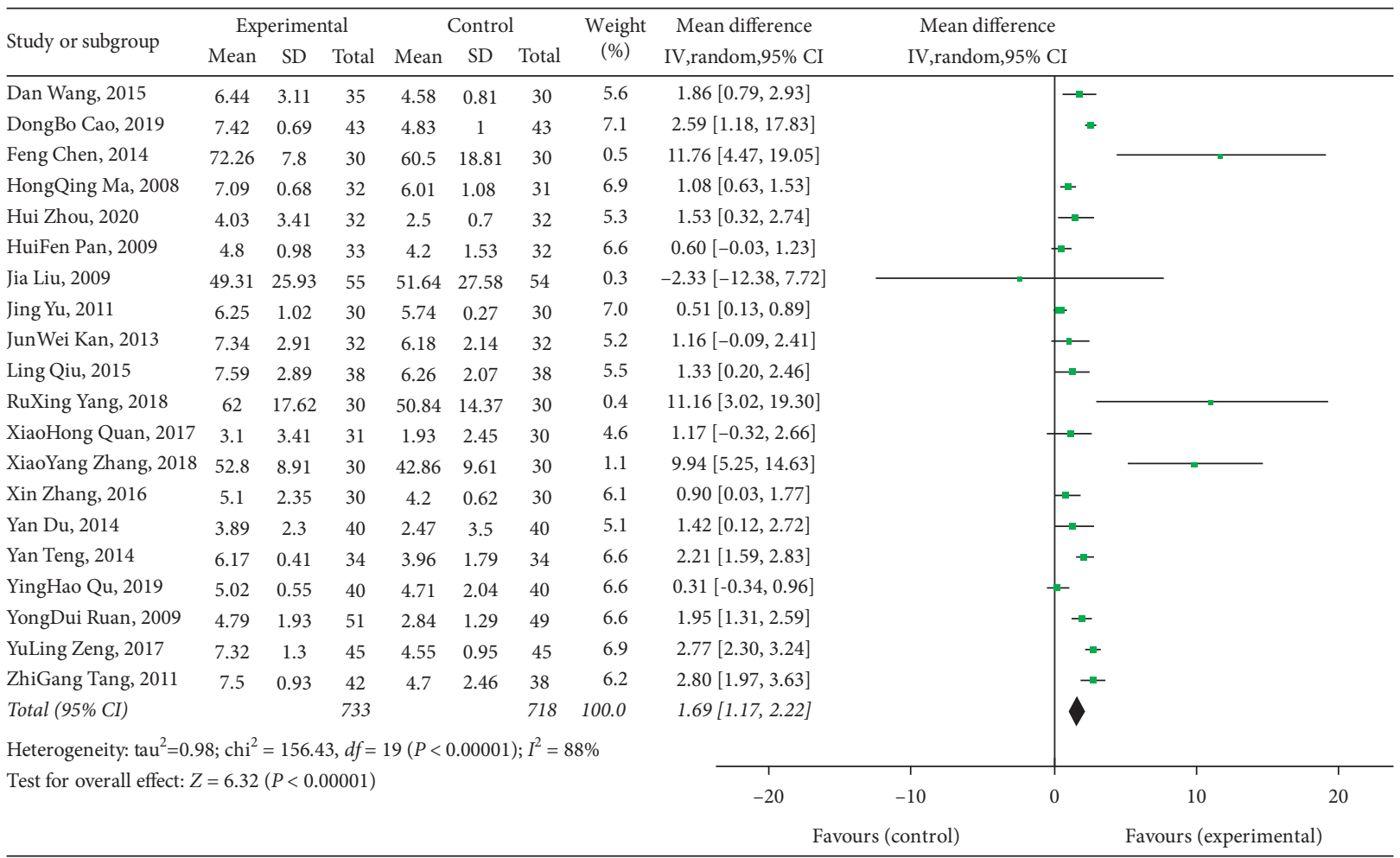

FIGURE 6: VAS pain score forest plot.

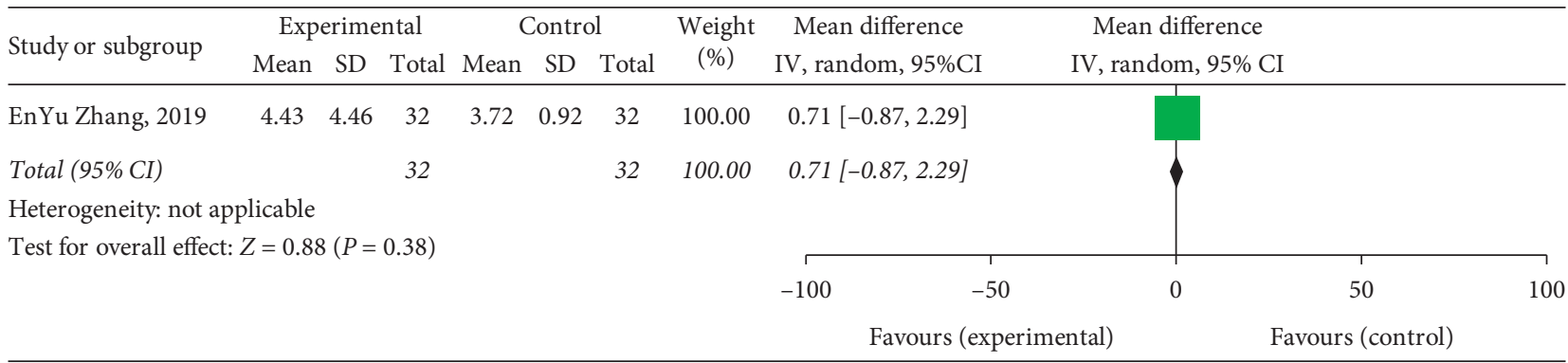

FIGURE 7: NRS funnel plot.

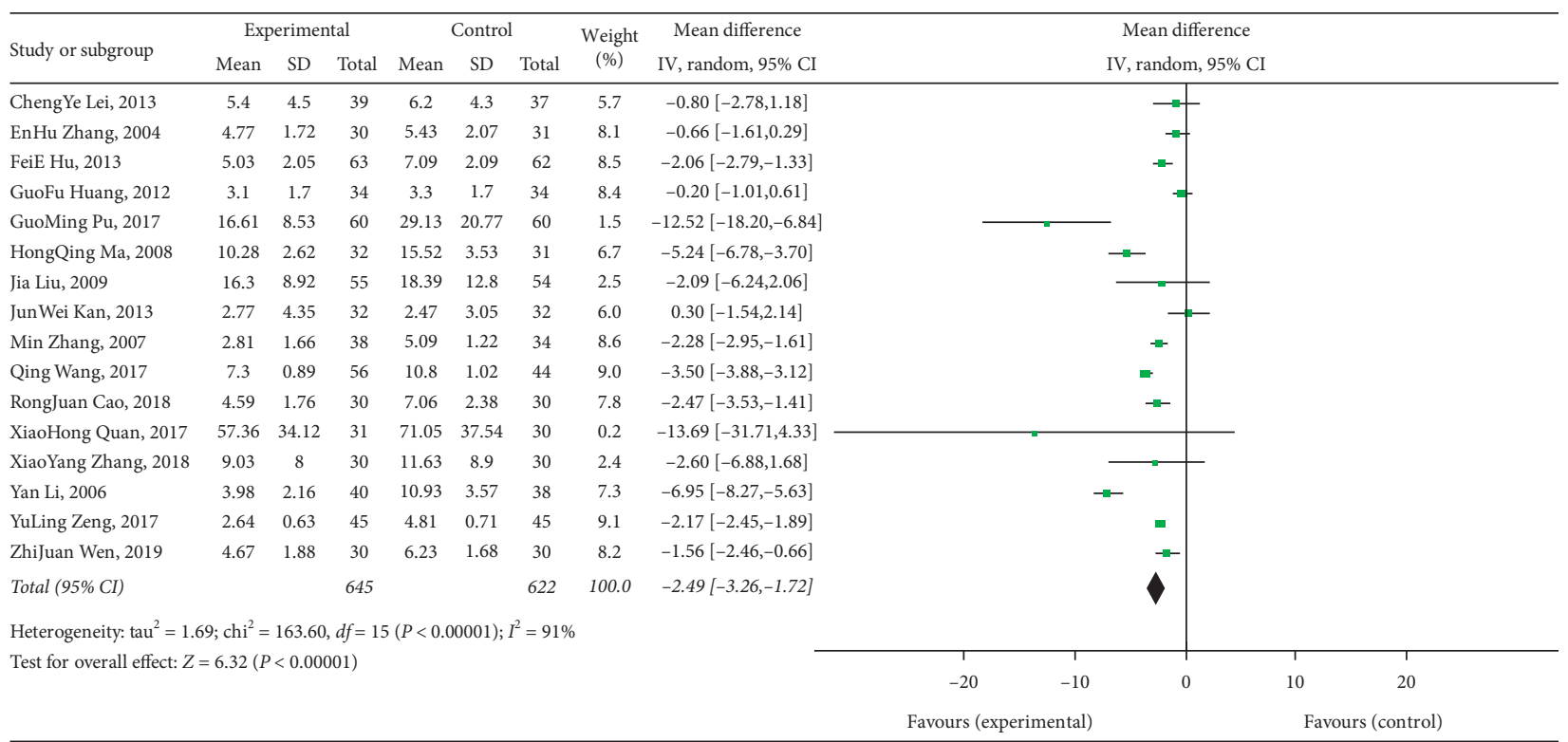

FIgUre 8: The time of analgesia forest plot. 


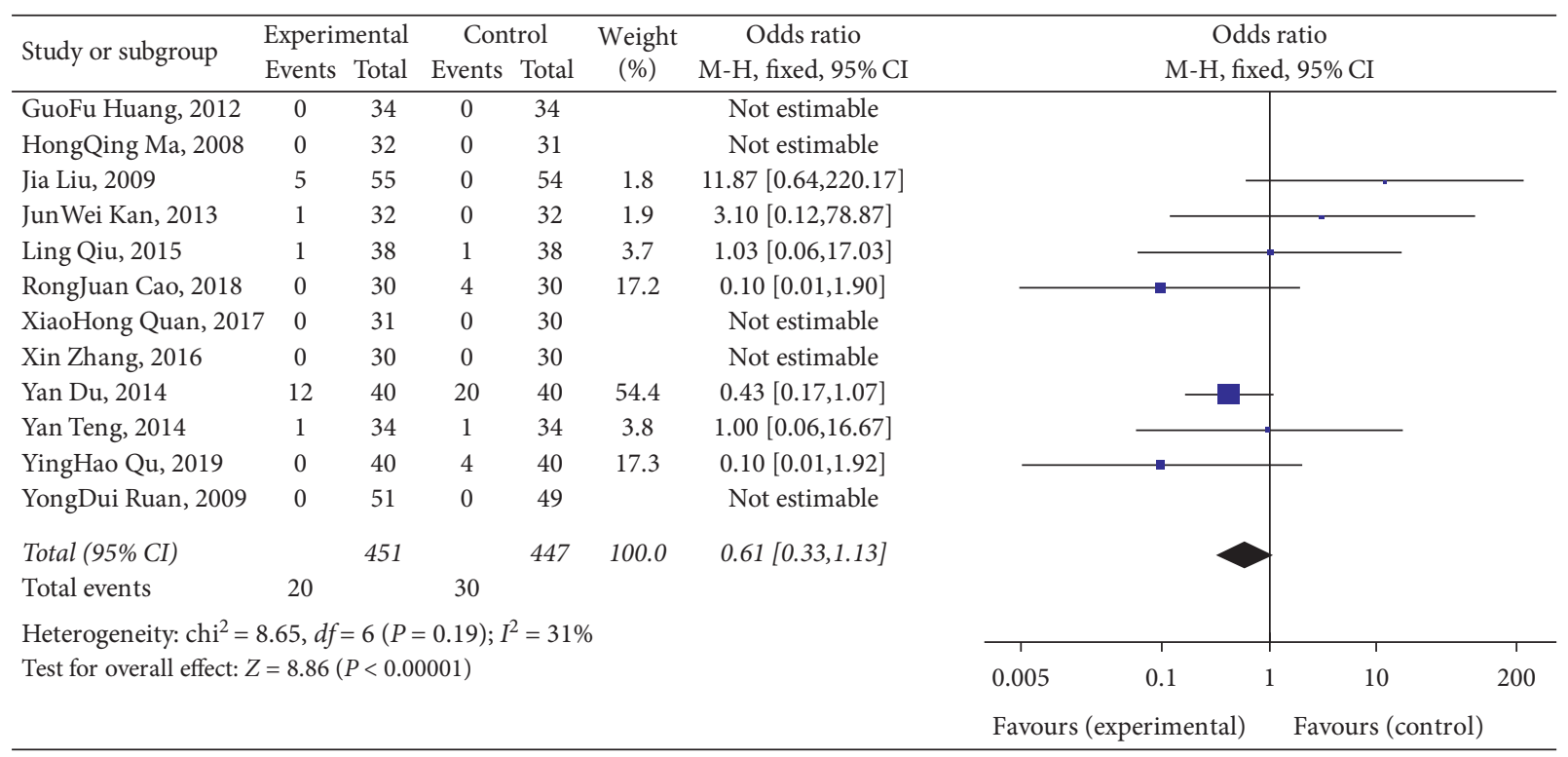

FIGURE 9: Adverse reaction forest plot.

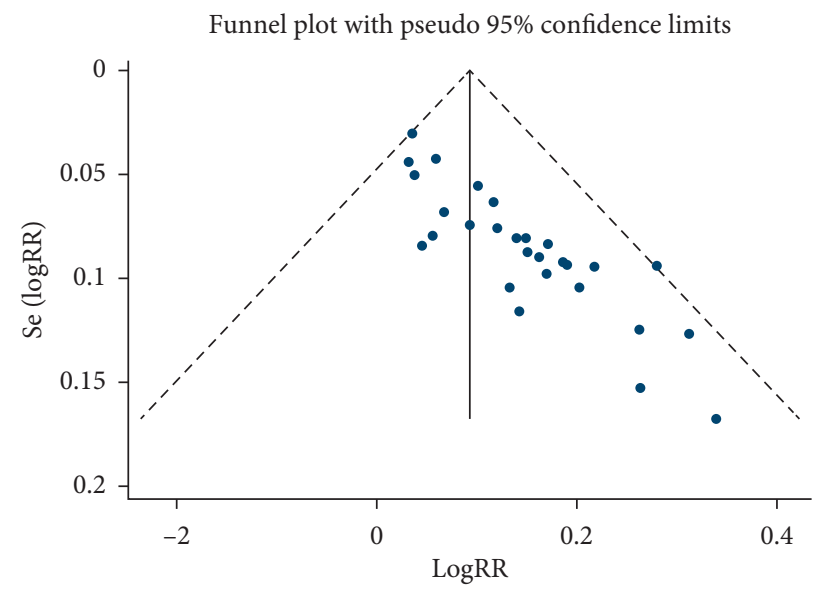

FIGURE 10: Funnel polt.

Begg's test

adj.kendall's score (P-Q) $=280$

Std. dev. of score $=53.31$

Number of studies $=29$

$z=5.25$

$\operatorname{Pr}>|z|=0.000$

$z=5.23$ (continuity corrected)

$\operatorname{Pr}>|z|=0.000$ (continuity corrected)

Egger's test

\begin{tabular}{lccccccc|}
\hline Std_eff & Coef. & Std. err. & $t$ & $\mathrm{P}>|t|$ & \multicolumn{2}{c|}{ [95\% conf. interval] } \\
\hline slope & -0.0502394 & 0.166517 & -3.02 & 0.006 & -0.0844058 & -0.0160729 \\
bias & 2.272308 & 0.2419102 & 9.39 & 0.000 & 1.775949 & 2.768667
\end{tabular}

Figure 11: Begg's test and Egger's test. 


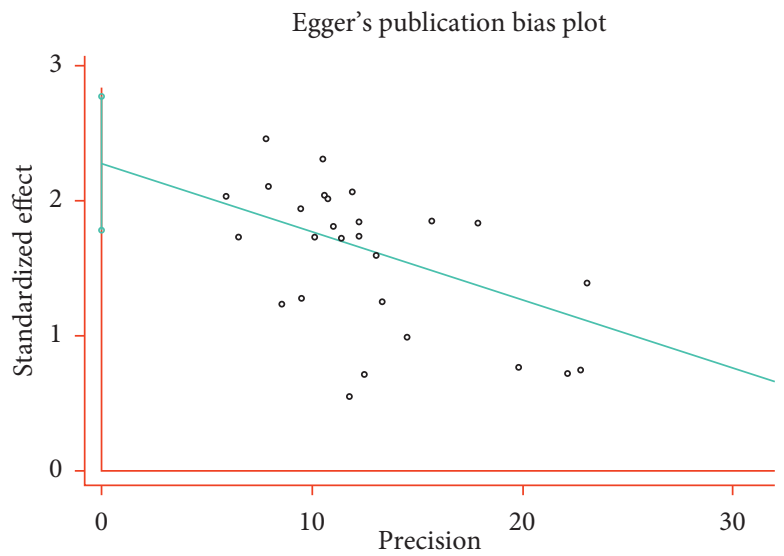

FIgURE 12: Egger's graph.

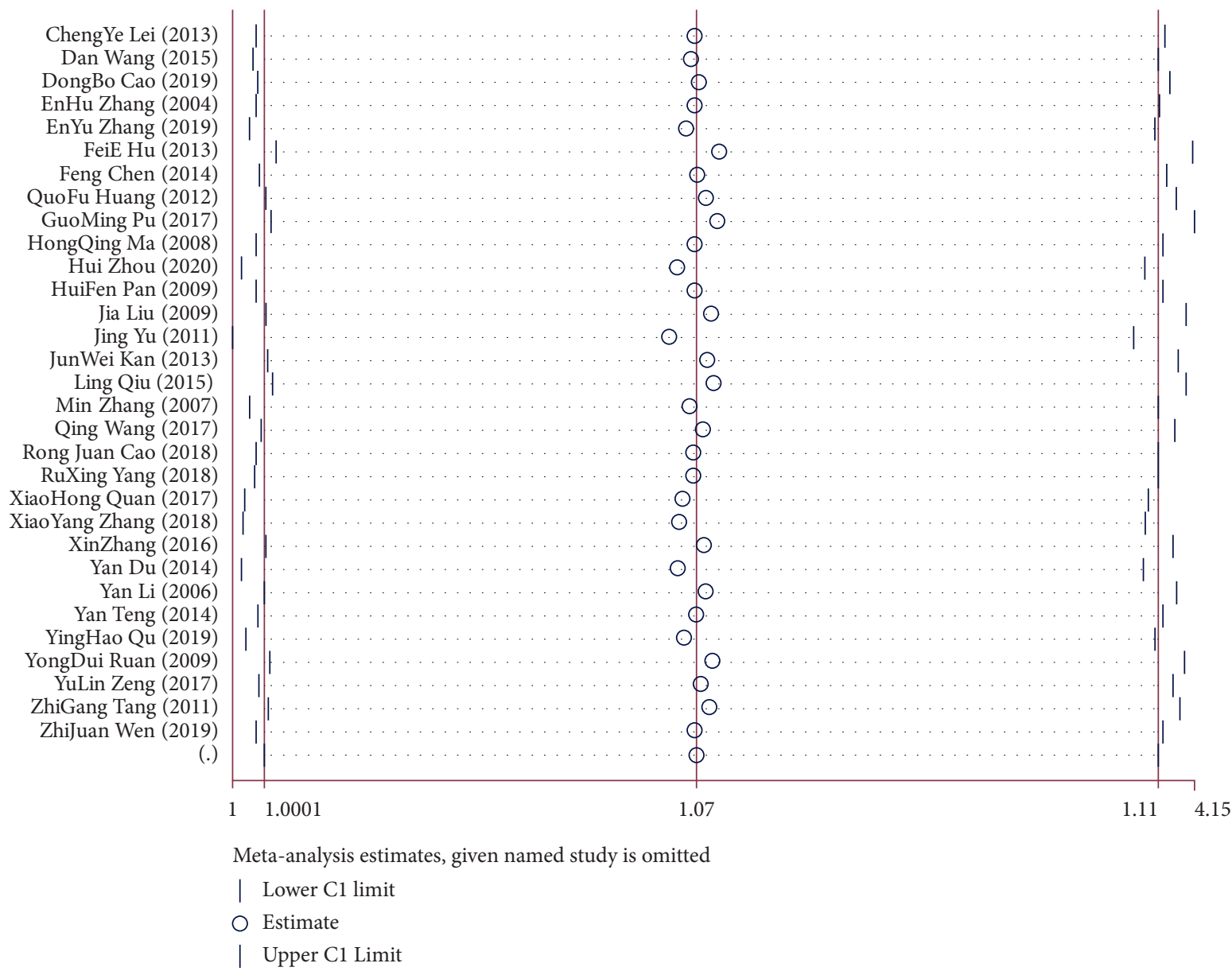

FIgURE 13: Sensitivity analysis. 


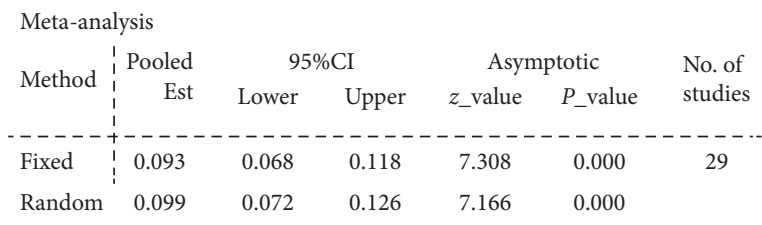

Test for heterogeneity: $Q=30.607$ on 28 degrees of freedom $(p=0.335)$

Moment-based estimate of between studies variance $=0.000$

Trimming estimator: linear

Meta-analysis type: fixed-effects model

\begin{tabular}{c:ccccc} 
Iteration & Estimate & Tn & \# to trim & Diff \\
\hdashline 1 & $:$ & 0.093 & 349 & 9 & 435 \\
2 & & 0.073 & 390 & 12 & 82 \\
3 & & 0.066 & 396 & 13 & 12 \\
4 & & 0.064 & 398 & 13 & 4 \\
5 & & 0.064 & 398 & 13 & 0
\end{tabular}

Filled

Meta-analysis (exponential form)

\begin{tabular}{|c|c|c|c|c|c|c|}
\hline \multirow[b]{2}{*}{ Method } & \multirow{2}{*}{$\begin{array}{c}\text { Pooled } \\
\text { Est }\end{array}$} & \multicolumn{2}{|c|}{$95 \% \mathrm{CI}$} & \multicolumn{2}{|c|}{ Asymptotic } & \multirow{2}{*}{$\begin{array}{l}\text { No. of } \\
\text { studies }\end{array}$} \\
\hline & & Lower & Upper & $z \_$value & $P_{\text {_value }}$ & \\
\hline xed & 1.066 & 1.042 & 1.091 & 5.514 & 0.000 & 42 \\
\hline ndom & 1.072 & 1.040 & 1.106 & 4.401 & 0.000 & \\
\hline
\end{tabular}

Test for heterogeneity: $Q=64.691$ on 41 degrees of freedom $(p=0.011)$

Moment-based estimate of between studies variance $=0.003$

FIGURE 14: Calculation results of the trim and filling method.

Filled funnel plot with pseudo 95\% confidence limits

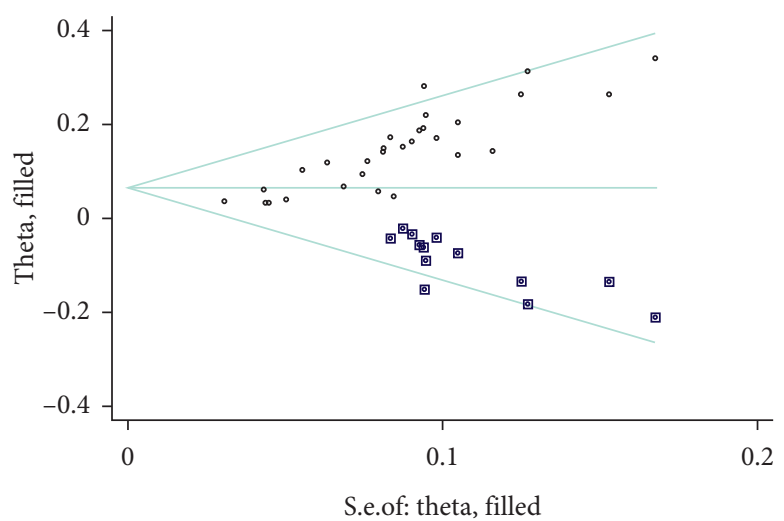

Figure 15: Trim and filling method. methods, most studies have not mentioned allocation concealment and blindness methods, and diagnostic criteria and efficacy evaluation criteria are not completely unified, all of which can lead to publication bias. (4) Half of the studies did not have follow-up and adverse reactions reported, and there was insufficient evidence for safety evaluation.

\section{Conclusions}

The moxibustion has certain advantages in treating $\mathrm{HZ}$ and PHN and relieving neuralgia. The obvious publication bias affects the credibility of this result, and more high-quality, large-sample randomized controlled clinical studies should be included in the future to improve the credibility of the result. Meanwhile, more rigorous randomized controlled studies and longer follow-up time are expected in the future to provide reliable clinical evidence for the short-term and long-term efficacy and safety evaluation of moxibustion in the treatment of $\mathrm{HZ}$ and PHN.

\section{Data Availability}

No datasets were generated or analysed during the current study. 


\section{Consent}

Informed consent was obtained from all individual participants included in the study references.

\section{Conflicts of Interest}

The authors declare that there are no conflicts of interest.

\section{Acknowledgments}

This work was funded by the "Hundred Talents Project" of the Affiliated Hospital of Chengdu University of Traditional Chinese Medicine, No. P2020042, and "Hundred Talents Project" of the Affiliated Hospital of Chengdu University of Traditional Chinese Medicine.

\section{References}

[1] B. Zhao, China Clinical Dermatology, Jiangsu Phoenix Science and Technology Press, Nanjing, China, 2017.

[2] A. Salvetti, V. Ferrari, R. Garofalo et al., "Incidence of herpes zoster and postherpetic neuralgia in Italian adults aged $\geq 50$ years: a prospective study," Preventive Medicine Reports, vol. 14, p. 100882, 2019.

[3] K. Hempenstall, T. J. Nurmikko, R. W. Johnson, R. P. A'Hern, and A. S. C. Rice, "Analgesic therapy in postherpetic neuralgia: a quantitative systematic review," PLoS Medicine, vol. 2, no. 7, p. e164, 2005.

[4] N. B. Finnerup, N. Attal, S. Haroutounian et al., "Pharmacotherapy for neuropathic pain in adults: a systematic review and meta-analysis," The Lancet Neurology, vol. 14, no. 2, pp. 162-173, 2015.

[5] M. E. Coyle, H. Liang, and K. Wang, "Acupuncture plus moxibustion for herpes zoster: a systematic review and metaanalysis of randomized controlled trials," Dermatologic Therapy, vol. 30, no. 4, 2017.

[6] W. Pei, J. Zeng, L. Lu, G. Lin, and J. Ruan, "Is acupuncture an effective postherpetic neuralgia treatment? a systematic review and meta-analysis," Journal of Pain Research, vol. 12, pp. 2155-2165, 2019.

[7] M. Avijgan, S. T. Hajzargarbashi, A. Kamran, and M. Avijgan, "Postherpetic neuralgia: practical experiences return to traditional Chinese medicine," Journal of Acupuncture and Meridian Studies, vol. 10, no. 3, pp. 157-164, 2017.

[8] X.-W. Li, Y.-K. Yang, X.-M. Xie, L.-N. Bai, and X.-S. Zhang, "Economic evaluation of treating herpes zoster with various methods of acupuncture and moxibustion," Journal of Traditional Chinese Medicine, vol. 32, no. 1, pp. 125-128, 2012.

[9] L. Fan-Rong and W. Hua, Acupuncture, Chinese Press of Traditional Chinese Medicine, Beijing, China, 2016.

[10] H. Kai-Yu, L. Shuang, and H. Guang-Yong, "From biological effects of local cutaneous thermal stimulation to moxibustion therapy," Acupuncture Research, vol. 40, no. 6, pp. 504-509, 2015.

[11] K. K. Petersen, M. L. Rousing, and C. Jensen, "Effect of local controlled heat on transdermal delivery of nicotine," International Journal of Physiology, Pathophysiology and Pharmacology, vol. 3, no. 3, pp. 236-242, 2011.

[12] X. M. Yu, G. M. Zhu, and Y. L. Chen, "Systematic assessment of acupuncture for treatment of herpes zoster in domestic clinical studies," Zhongguo Zhen Jiu, vol. 27, no. 7, pp. 536540, 2007.
[13] J. X. Wang, W. X. Zhao, and J. C. Zeng, "Systematic review and sequential analysis on treatment of herpes zoster pain mainly by fire needle therapy," Zhen Ci Yan Jiu, vol. 44, no. 9, pp. 677-685, 2019.

[14] X. Y. Zhang, W. X. Wang, and L. Y. Rong, "Clinical observation of cotton moxibustion treatment of herpes zoster with "treating febrile disease with heat," Guiding Journal of Traditional Chinese Medicine and Pharmacology, vol. 24, no. 22, 2018.

[15] G. F. Huang, H. X. Zhang, Z. S. Xu, and J. C. Li, "Comparison of therapeutic effects of different types of acupuncture interventions on herpes zoster in acute stage," Acupuncture Research, vol. 37, no. 5, 2012.

[16] J. Liu, Clinical Effect Evaluation of a RCT for Cotton-Sheet Clinical Effect Evaluation of a RCT for Cotton-Sheet Moxibustion Therapy in Patients with Herpes Zoster, Chengdu University of Traditional Chinese Medicine, Chengdu, China, 2009.

[17] X. H. Quan, Medicated Thread Moxibustion Treatment of Liver Meridian Stagnated-Heat Type of Herpes Zoster in Acute Phase: A Clinical Trial, Guangzhou University of Chinese Medicine, Guangzhou, China, 2017.

[18] F. Chen, "The clinical study on the therapy of line medicine moxibustion which was combined with electro-acupuncture, pricking-cupping bloodletting method treating acute herpes zoster," Master thesis, Guangzhou University of Chinese Medicine, Guangzhou, China, 2014.

[19] Y. Du, Y. L Huang, R. P. Wei et al., "Clinical study on medicated thread moxibustion of traditional Zhuang nationality medicine combined with acupuncture on postherpetic neuralgia," Liaoning Journal of Traditional Chinese Medicine, vol. 41, no. 8, 2014.

[20] F. E. Hu, Z. Y. Li, and Z. R. Huang, "Clinical observation of treating acute herpes zoster with moxibustion," Guangxi Journal of Traditional Chinese Medicine, vol. 36, no. 1, 2013.

[21] M. Zhang, L. Qiu, and J. Zhang, "Observation on therapeutic effect of surround needling plus surround moxibustion on herpes zoster," Chinese Acupuncture Plus Moxibustion, vol. 27, no. 2, 2007.

[22] H. Zhou and J. H. Wang, "Curative observation of grainmoxibustion at sihua acupoints combined with surroundmoxibustion in treating postherpetic neuralgia," Journal of Guangzhou University of Traditional Chinese Medicine, vol. 37, no. 4, 2020.

[23] Z. J. Wen and S. S. Hu, "Clinical observation of herbalstring moxibustion combined with famciclovir treating herpes zoster," Chinese Journal of Ethnomedicine and Ethnopharmacy, vol. 28, no. 7, 2019.

[24] Z. G. Tang and S. S. Zhu, "Clinical observation on effect of burning rush moxibustion on the treatment of 42 herpes zoster patients," Hunan Journal of Traditional Chinese Medicine, vol. 27, no. 3, 2011.

[25] Y. L. Zeng, Y. N. Liu, and Q. Q. Liu, "Clinical observation on effect of burning rush moxibustion on the treatment of 45 herpes zoster patients," Yunnan Journal of Traditional Chinese Medicine and Materia Medica, vol. 38, no. 10, 2017.

[26] Y. D. Ruan, W. Z. Wei, Y. F. Xie et al., Observation of therapeutic effect on postherpetic neuralgic treated with acupoint heat-sensitization, p. 4, 2009.

[27] Y. H. Qu, L. T. Liang, and D. N. Wu, "Clinical observation on wick moxibustion in the reatment of acute herpes zoster," Guangming Journal of Chinese Medicine, vol. 34, no. 18, 2019. 
[28] J. Yu, Curative Effect Observation on the Postherpetic Neuralgia with Round Acupuncture and DU Moxibustion, Hubei University of Chinese Medicine, Wuhan, China, 2011.

[29] Y. Teng, Y. F. Zhang, and Q. Wang, "Random parallel control study of treatment of postherpetic neuralgia with needle warming moxibustion combined with moxa-moxibustion at Jiaji points," Journal of Practical Traditional Chinese Internal Medicine, vol. 28, no. 2, 2014.

[30] Y. Li and C. H. Liu, "Electroacupuncture combined with moxibustion in the treatment of 40 cases of senile postherpetic neuralgia," Journal of Nanjing University of Chinese Medicine, vol. 22, no. 5, pp. 332-333, 2006.

[31] M. Zhang, Clinical Study on the Treatment of Postherpetic Neuralgia with Qi Stagnation and Blood Stasis Type by Surround Needling Combined with Thunder Fire moxibustion, Changchun University of Chinese Medicine, Changchun, China, 2017.

[32] R. X. Yang and F. S. Qiu, "Therapeutic observation of wick moxibustion in treatment of acute-stage herpes zoster," Shanghai Journal of Acupuncture and Moxibustion, vol. 37, no. 7, 2018.

[33] R. J. Cao, X. H. Qiu, and X. J. Lan, "Clinical observation of cotton moxibustion therapy for herpes zoster," Fujian Journal of Traditional Chinese Medicine, vol. 49, no. 3, 2018.

[34] Q. Wang, G. J. Chen, W. Y. Yi et al., "Observation on nursing effect of sparrow-pecking moxibustion on 56 cases of herpes zoster," World Chinese Medicine, vol. 12, no. A01, 2017.

[35] L. Qui, X. Zhang, J. W. Kan et al., "Middle aged patients with postherpetic neuralgia treated with grain-moxibustion combined with acupuncture: a clinical observation on 40 cases," Journal of Traditional Chinese Medicine, vol. 56, no. 22, pp. 1931-1934, 2015.

[36] J. W. Kan, Clinical Observation on the Treatment of Postherpetic Neuralgia with Wheat Moxibustion Combined with Electric Acupuncture on Jiaji Point Plus Surround Needling, Chengdu University of Traditional Chinese Medicine, Chengdu, China, 2013.

[37] H. F. Pan and Z. P. Zhang, "Clinical observation of cotton moxibustion in treating 33 cases of herpes zoster," Guiding Journal of Traditional Chinese Medicine and Pharmacy, vol. 15, no. 7, pp. 58-59, 2009.

[38] H. Q. Ma, Clinical Study on the Treatment of Postherpetic Neuralgia by Ashi Point Direct Moxibustion Plus Encircled Needling, Chengdu University of Traditional Chinese Medicine, Chengdu, China, 2008.

[39] G. M. Pu, H. C. Zhang, and S. J. Liu, "Clinical evaluation of cotton spread moxibustion therapy and western medicine therapy for herpes zoster," Journal of Clinical Medical, vol. 4, no. 28, 2017.

[40] E. Y. Zhang, Y. L. Zhang, and J. Zhou, "Clinical observation of 32 cases of postherpetic neuralgia treated by acupuncture plus moxibustion," Hunan Journal of Traditional Chinese Medicine, vol. 35, no. 1, pp. 72-73, 2019.

[41] E. H. Zhang, "Treatment of cases of herpes zoster with moxibustion," Journal of NanJing TCM University, vol. 20, no. 6, 2004.

[42] D. B. Cao, "Clinical study on the treatment of postherpetic neuralgia by invigorating Qi and removing blood stasis and Tongluo combined with heat-sensitive moxibustion," Guiding Journal of Traditional Chinese Medicine and Pharmacology, vol. 24, no. 24, 2018.

[43] D. Wang, Y. Liang, and L. M. Chen, "Clinical study on treatment of elderly herpes zoster with moxibustion on heat- sensitive acupoints combined with erwei badu powder," Chinese Journal of Information on TCM, vol. 22, no. 4, 2015.

[44] C. Y. Lei, X. F. Xue, Y. Ye et al., "Clinical observation of 39 cases of thunder fire moxibustion treated with herpes zoster," Chinese Medicine Modern Distance Education of China, vol. 11, no. 13, 2013.

[45] B. A. Weaver, "The burden of herpes zoster and postherpetic neuralgia in the United States," Journal of the American Osteopathic Association, vol. 107, no. 3 Suppl 1, pp. S2-S7, 2007.

[46] M. Drolet, M. Brisson, K. E. Schmader et al., "The impact of herpes zoster and postherpetic neuralgia on health-related quality of life: a prospective study," Canadian Medical Association Journal, vol. 182, no. 16, pp. 1731-1736, 2010.

[47] Y. J. Kim, C. N. Lee, M. S. Lee et al., "Recurrence rate of herpes zoster and its risk factors: a population-based cohort study," Journal of Korean Medical Science, vol. 34, no. 2, p. e1, 2019.

[48] H. J. Forbes, K. Bhaskaran, S. L. Thomas et al., "Quantification of risk factors for postherpetic neuralgia in herpes zoster patients," Neurology, vol. 87, no. 1, pp. 94-102, 2016.

[49] K. Kawai, B. G. Gebremeskel, and C. J. Acosta, "Systematic review of incidence and complications of herpes zoster: towards a global perspective," BMJ Open, vol. 4, no. 6, Article ID e004833, 2014.

[50] J. Schutzer-Weissmann and P. Farquhar-Smith, "Post-herpetic neuralgia-a review of current management and future directions," Expert Opinion on Pharmacotherapy, vol. 18, no. 16, pp. 1739-1750, 2017.

[51] G. M. Sacks, "Unmet need in the treatment of postherpetic neuralgia," American Journal of Managed Care, vol. 19, no. 1 Suppl, pp. S207-S213, 2013.

[52] G. Gabutti, N. Valente, P. Kuhdari, S. Lupi, and A. Stefanati, "Prevention of herpes zoster and its complications: from the clinic to the real-life experience with the vaccine," Journal of Medical Microbiology, vol. 65, no. 12, pp. 1363-1369, 2016.

[53] S. Esposito and N. Principi, "Herpes zoster prevention: a difficult problem to solve," Vaccine, vol. 36, no. 36, pp. 5442-5448, 2018.

[54] F. Brosio, G. Masetti, G. Matteo, A. Stefanati, and G. Gabutti, "A novel nonlive, adjuvanted herpes zoster subunit vaccine: a report on the emerging clinical data and safety profile," Infection and Drug Resistance, vol. 11, pp. 1401-1411, 2018.

[55] A. F. Dagnew, O. Ilhan, and W. S. Lee, "Immunogenicity and safety of the adjuvanted recombinant zoster vaccine in adults with haematological malignancies: a phase 3, randomised, clinical trial and post-hoc efficacy analysis," Lancet Infectious Diseases, vol. 19, no. 9, pp. 988-1000, 2019. 